\title{
Diagnosis of melanoma under concomitant natalizumab therapy
}

\author{
Vavricka, B M P ; Baumberger, P ; Russmann, S ; Kullak-Ublick, G A
}

DOI: https://doi.org/10.1177/1352458510389629

Posted at the Zurich Open Repository and Archive, University of Zurich ZORA URL: https://doi.org/10.5167/uzh-46541

Journal Article

Accepted Version

Originally published at:

Vavricka, B M P; Baumberger, P; Russmann, S; Kullak-Ublick, G A (2011). Diagnosis of melanoma under concomitant natalizumab therapy. Multiple Sclerosis, 17(2):255-256.

DOI: https://doi.org/10.1177/1352458510389629 


\section{Letter to the Editor}

\section{Diagnosis of Melanoma Under Concomitant Natalizumab Therapy}

Bettina M. Prinz Vavricka MD ${ }^{1,2}$, Peter Baumberger MD ${ }^{3}$, Stefan Russmann MD ${ }^{1}$, Gerd A. KullakUblick $\mathrm{MD}^{1}$

${ }^{1}$ Division of Clinical Pharmacology and Toxicology, University Hospital Zurich, Switzerland,

${ }^{2}$ Division of Dermatology, University Hospital Zurich, Switzerland

${ }^{3}$ Neurology, Private practice, Frauenfeld, Switzerland

Funding sources: none

Conflicts of interest: None declared

\section{Correspondence:}

Gerd A. Kullak-Ublick, MD

Division of Clinical Pharmacology and Toxicology

University Hospital

Raemistrasse 100

$\mathrm{CH}-8091$ Zurich

Switzerland

Phone: +4144255 4097

Fax: $\quad+41442554411$

e-mail: gerd.kullak@usz.ch 
To the Editor: We have read with great interest the short report on natalizumab and melanoma from Bergamaschi and Montomoli published recently in this journal. ${ }^{1}$ Natalizumab (Tysabri, Biogen Idec and Elan Pharmaceuticals) is a humanized monoclonal antibody against $\alpha_{4}$ integrins used in the treatment of multiple sclerosis and Crohn's disease. ${ }^{2}$ Mullen et al reported on two cases of melanoma in patients with multiple sclerosis receiving natalizumab. ${ }^{3}$ Their letter was criticized since case reports in general show limited interpretability in establishing cause-and-effect relationships ${ }^{3}$ and since controlled clinical trials and postmarketing surveillance studies did not indicate an increased risk of melanoma in patients receiving natalizumab. ${ }^{2}$ However, melanoma is underreported to cancer registries as compared to other cancers due to its occurrence in the outpatient setting ${ }^{5}$ and therefore, postmarketing surveillance studies might also underestimate the true incidence of melanomas as side-effect of any drug therapy. We report here on a 41-year-old woman who had been treated with natalizumab (once per month i.v.) for 15 months for multiple sclerosis. The patient had no known history of melanoma but displayed many atypical moles for years that were regularly checked by a dermatologist. The family history was negative for melanomas and she did not expose herself to sunlight regularly. She noticed a rapidly growing mole on her upper arm. On evaluation it proved to be a superficial spreading melanoma in situ pTis (SSM-type) on the basis of a dysplastic nevus of a compound-type. The lesion was excised in total. Other moles were also removed but did not show any histological signs of melanoma. An eye examination with a special focus on the retina revealed no signs of ocular melanoma. The patient is now on regular follow-up with a dermatologist and showed no other transdifferentiation of the known nevi. She is still on natalizumab therapy.

The occurrence of melanoma in our patient was in close temporal relation to the administration of natalizumab and an alteration in a long-standing nevus. It should be taken into account that anti- $\alpha_{4}$ integrin antibodies suppress the immune system by inducing apoptosis in lymph-node T cells in an in vitro model ${ }^{6}$ which could explain the potential of melanoma cells to spread. The already published case reports together with the present case report should raise the awareness of this possible side effect of developing melanoma under natalizumab therapy. Medical doctors using natalizumab should consider regular dermatological check-ups for their patients until further data are available. 
References

1. Beergamaschi R, Montomoli C. Melanoma in multiple sclerosis treated with natalizumab: causal association or coincidence?. Multiple Sclerosis 2009; 15: 1532-1533.

2. Polman $\mathrm{CH}, \mathrm{O}$ 'Connor PW, Havrdova E, et al. A randomized, placebo-controlled trial of natalizumab for relapsing multiple sclerosis. N Engl J Med 2006; 354:899-910.

3. Mullen JT, Vartanian TK, Atkins MB. Melanoma complicating treatment with natalizumab for multiple sclerosis. N Engl J Med 2008;358: 647-648.

4. Panzara MA, Bozic C, Sandrock AW. More on melanoma with transdifferentiation. N Engl J Med 2008; 359:99.

5. Cockburn M, Swetter SM, Peng D, Keegan TH, Deapen D, Clarke CA. Melanoma underreporting: why does it happen, how big is the problem, and how do we fix it? J Am Acad Dermatol 2008; 59: 1081-1085.

6. Tchilian EZ, Owen JJ, Jenkinson EJ. Anti-alpha 4 integrin antibody induces apoptosis in murine thymocytes and staphylococcal enterotoxin B-activated lymph node T cells. Immunology 1997; 92:321-327. 